\title{
Impact of Walking on Adipose Tissue Lipoprotein Lipase Activity and Expression in Pre- and Postmenopausal Women
}

\author{
Sebastien Tessier ${ }^{a, b *}$ Éléonor Riesco ${ }^{c *}$ Michel Lacaille ${ }^{a}$ Francine Pérusse $^{b}$ \\ John Weisnagel ${ }^{a, d}$ Jean Doréa Pascale Mauriège ${ }^{a, b}$ \\ ${ }^{a}$ Division of Kinesiology, Laval University,

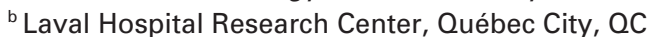 \\ ${ }^{\mathrm{c}}$ Research Center on Aging, IUGS, Sherbrooke, QC, \\ ${ }^{\mathrm{d}}$ Diabetes Research Unit, CHUL Research Center, Québec City, QC, Canada
}

\section{Keywords}

Lipid storage - Menopause - Obesity · Exercise ·

Metabolic profile

\section{Summary}

Objective: The aim of this study was to examine regional variation in adipose tissue lipoprotein lipase (AT-LPL) activity and expression in pre- and postmenopausal women, before and after training, once differences in chronological age or obesity degree are taken into account. Methods: Sixteen late pre- and 14 early postmenopausal ( $49 \pm 2$ vs. $52 \pm 2$ years; $p<0.001)$ moderately obese women (body mass index $29-35 \mathrm{~kg} / \mathrm{m}^{2}$ ) were subjected to a 16-week walking program (3 sessions/week of $45 \mathrm{~min}$ at $60 \%$ heart rate reserve). Abdominal and femoral AT-LPL activity and expression, fasting lipidlipoprotein profile, body composition, and cardiorespiratory fitness (CRF) were measured before and after our intervention. Statistical analyses were performed using covariance analysis for age differences. Results: AT-LPL activity and expression, lipid-lipoprotein metabolism, body fatness, and CRF were similar at baseline, irrespective of the group considered. Slight reductions in plasma cholesterol and high-density lipoprotein (HDL) cholesterol levels, fat mass and waist girth reductions, CRF increases as well as femoral AT-LPL activity and expression decreases after our intervention were comparable, regardless of menopausal status $(0.0001<p<0.05)$.

*Both co-authors equally contributed to this work.
Conclusions: Lipid storage is decreased in the femoral depot after walking, regardless of menopausal status. Reduction in AT-LPL activity or expression does not lead to a more deleterious lipid-lipoprotein profile, despite the modest decrease noted in HDL cholesterol concentrations.

\section{Introduction}

Numerous studies have already pointed out that premenopausal women tend to accumulate excess fat predominantly in the gluteo-femoral areas which may, to a certain extent, be cardioprotective, while postmenopausal women display a preferential abdominal fat deposition associated with an increased risk of metabolic complications $[1,2]$. In this regard, regional variation in adipose tissue lipoprotein lipase (AT-LPL) activity, a key regulator of lipid storage [3], has already been hypothesized to account for differences in body fat distribution occurring during the transition to menopause [4]. Indeed, AT-LPL activity is higher in the gluteo-femoral than in the abdominal region in premenopausal women [5-8], although discordant results concerning the presence $[6,9]$ or absence of regional variation in this enzyme activity were reported in postmenopausal women [7, 10,11]. Main reasons for these conflicting data could be i) the lack of clear identification of women being in their perimenopausal phase [9], ii) that premenopausal women were examined in the luteal phase [6] or at any point of their menstrual cycle [7], iii) the use or not of hor-

Pascale Mauriège, Ph.D.

Division of Kinesiology, Department of Social and Preventive Medicine Laval University

PEPS, local 0216, G1V 0A6, Québec, QC, Canada

Tel. +1 418 656-2131, Fax -2441

Pascale.Mauriege@kin.msp.ulaval.ca 
mone therapy (HT) by women at menopause [7, 11-13], and iv) that pre- and postmenopausal women studied were not matched for age, adiposity, and regional fat distribution [6, 7]. The existence of site differences in AT-LPL mRNA levels has also been documented in pre- $[5,14]$ but not in postmenopausal women. However, the regulatory effects of ovarian hormone deficiency on regional variation in AT-LPL activity and/or expression has never been investigated, once differences in women's chronological age and/or obesity degree are taken into account.

On the other hand, previous studies that assessed the impact of different weight loss strategies including surgery, hypocaloric diet alone or combined with drugs or aerobic exercise on AT-LPL activity, have shown either a decrease [15] or a lack of change $[10,16,17]$, whereas others have observed an increase in the enzyme activity [18-20]. Very little information on the effect of aerobic exercise alone on AT-LPL activity is, however, available with the exception of one study [21] which clearly reported a decrease in this enzyme activity at both the abdominal and femoral sites, after 6 months of endurance exercise, in obese premenopausal women. As LPL plays an important role in lipoprotein metabolism by catabolizing chylomicrons and very-low-density lipoprotein (VLDL) thus leading to the formation of high-density lipoprotein (HDL) cholesterol particles [22], we wondered whether changes in this enzyme activity and/or expression could have an impact on lipidlipoprotein metabolism. However, the impact of a physical activity different from a standardized laboratory exercise on regional variation in AT-LPL activity and/or expression has not yet been investigated in pre- and postmenopausal women carefully matched for age and obesity degree.

Primary aims of this study were thus i) to verify whether regional variations in both AT-LPL activity and expression persist at early menopause when compared to late premenopausal status, once age and obesity degree differences are taken into account, and ii) to evaluate the impact of a 16-week walking program on AT-LPL activity and mRNA level. A secondary objective was to examine whether changes in the enzyme activity and/or expression were related to a more favourable or deleterious lipid-lipoprotein profile.

\section{Material and Methods}

\section{Subjects}

Healthy Caucasian women were recruited from the suburbs of Québec City to participate in a 16-week walking program, the Menopause Obesity and Exercise study (MenOEx), through an announcement in local newspapers. From a total of 48 women who responded, 35 participants met the following inclusion criteria: None of the women had identified cardiomyopathy, endocrine disorders which may have caused irregular menstrual cycles, or orthopaedic limitations that would affect physical activity. They had to be non-smokers and moderate consumers of alcohol and caffeine. Their body weight had to be stable (less than $2 \mathrm{~kg}$ weight change) in the year before the onset of the study. All participants also had to be sedentary (exercising less than 30 min per week), and moderately obese (body mass index (BMI) ranging from 29 to $35 \mathrm{~kg} / \mathrm{m}^{2}$ ). Women on medication that could potentially influence the outcome of this study $(\beta$-blockers, sympathomimetics, cholesterol-lowering drugs including statins, corticosteroids, antihypertensive drugs, and thyroxine for which a dosage change occurred during the last 6 months) were excluded from the present study. Premenopausal status was defined as the occurrence of 2 menses in the 3 last months, the absence of cycle irregularity in the 12 months preceding testing, mean cycle length of 24-30 days, and plasma follicle-stimulating hormone (FSH) levels lower than 30-40 IU/1. In this regard, all premenopausal women from the present study had plasma FSH levels lower than 40 IU/l. In addition, postmenopausal status was defined by amenorrhea for at least 12 months but no longer than 5 years, and plasma FSH levels greater than 30-40 IU/1 (North American Menopause Society, 2000). In this regard, Henrich et al. [23] have already shown the existence of a considerable overlap among distributions of FSH by stage on a representative sample of 576 US women aged 35-60 years examined during the National Health and Nutrition Examination Survey (NHANES) 1999-2000. Indeed, FSH cut-off points between the reproductive and menopause transition stages as well as between the menopause transition and postmenopausal stages were neither sensitive nor very specific, thus emphasizing that FSH levels had limited utility in discriminating among women in different stages. Although the physiological and clinical manifestations of transition to menopause are still not well understood, perimenopause, a time of menstrual irregularity lasting between 2 and 8 years [24-26], seems to occur in stages. During perimenopause, FSH concentrations may raise to the postmenopause range during some cycles, but return to premenopausal levels during subsequent cycles. As FSH levels also fluctuate from month to month during this phase $[24,25]$, the perimenopausal status cannot thus be clearly established. It is the reason why perimenopausal women with irregular menses were excluded from our study. According to the Stages of Reproductive Aging Workshop (STRAW), late premenopausal (e.g. reproductive) stage refers to women with regular menstrual cycles associated with either normal or slightly increased plasma FSH levels [27]. Finally, premenopausal women using oral contraceptives and postmenopausal women on HT were excluded from the present study (table 1).

\section{Study Design}

The experimental design was approved by the University Ethical Committee on Human Research for Medical Sciences, and all participants gave their written informed consent to participate in this study, conformed to the Laval University Medical Ethics Committee. Before entering our protocol, all women had a physical examination which included a resting electrocardiogram, by our physicians. The exercise program was planned according to the American College of Sports and Medicine recommendations [28], and consisted of 3 non-consecutive sessions/week of 45 min walking in indoor community facilities (PEPS), at approximately $60 \%$ of heart rate (HR) reserve (HRR) (e.g. the maximal HR minus the resting HR), during 16 weeks. Maximal HR was calculated from the following equation: 220 - age, where age is expressed in years. Walking HR was calculated as percentage HRR + resting HR, according to Karvonen et al. [29]. The 3-weekly walking sessions were supervised by an exercise leader. From the 35 women ( 18 pre- and 17 postmenopausal) who began the endurance exercise program, 16 late premenopausal women, $49 \pm 2$ years old (mean \pm standard deviation, SD), and 14 early postmenopausal women $52 \pm 2$ years old completed our study and had the pre- and postintervention fat biopsies. Reasons for drop out of 2 pre- and 3 postmenopausal women were illness $(n=1)$, re-location $(n=1)$, or wish to perform more exercise than the 3 sessions/week planned $(n=3)$.

Adipose Tissue Biopsy Procedure and Lipoprotein Lipase Activity After an overnight fast, participants were subjected to biopsies of subcutaneous fat, one performed in the periumbilical region (abdominal site) and the other at the anterior midthigh level (femoral site). Local anaesthesia (1\% xylocaine, without epinephrine) was performed in such a way that it 
Table 1. The STRAW staging system [27]
Final Menstrual Period

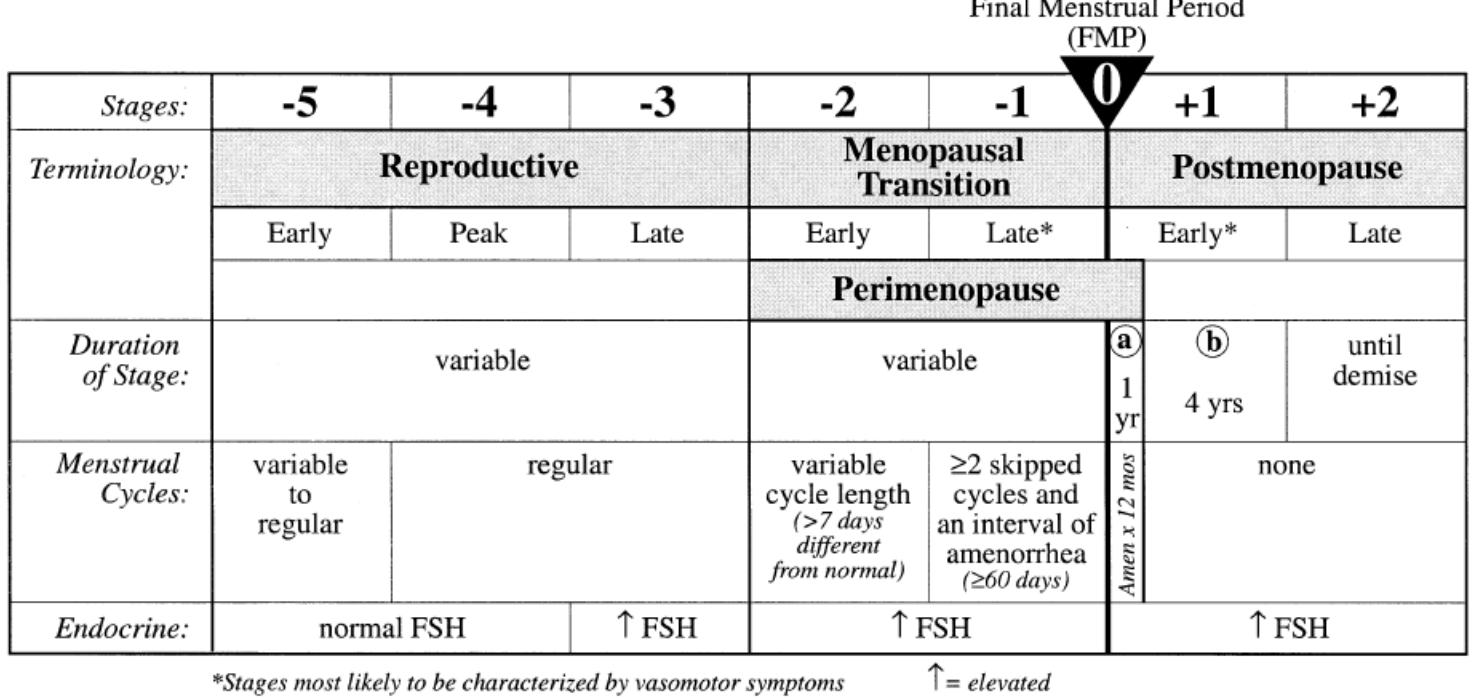

did not influence the metabolic activity of excised adipose tissue (AT) [30]. Biopsies were performed before and 2-4 weeks after the end of the training period. All women had to remain inactive for $36 \mathrm{~h}$ to avoid acute effect of exercise on AT metabolism before our post-intervention [31]. For premenopausal women, biopsies were performed while they were in the follicular phase of their menstrual cycle (e.g. between the 5th and the 12th days of their menstrual cycle). Approximately $100 \mathrm{mg}$ of AT from each region were immediately frozen in liquid nitrogen for later measurement of heparinreleasable lipoprotein lipase (LPL) activity, according to Imbeault et al. [5], and all experiments were run in duplicates. $\left[{ }^{14} \mathrm{C}\right]$-triolein was obtained from Perkin-Elmer and Analytical Sciences (Woodbridge, ON, Canada) whereas cold triolein came from Sigma-Aldrich (Oakville, ON, Canada). Another sample of $250 \mathrm{mg}$ AT was used for measurement of fat cell size. Adipocytes were isolated by collagenase digestion, and mean adipose cell diameter was assessed from the measurement of 300 cells [30].

\section{$R N A$ Preparation and Quantification of Lipoprotein Lipase} $m R N A$ Levels

Briefly, about 5-10 $\mu \mathrm{g}$ of total RNA was extracted from AT samples of $100 \mathrm{mg}$, using RNeasy Mini Kit (Qiagen, Mississauga, ON, Canada). The average yield of total RNA was $2.40 \pm 0.86$ and $2.80 \pm 1.66 \mu \mathrm{g} / 100 \mathrm{mg}$ AT (mean $\pm \mathrm{SD}$ ), for biopsies performed before and after our intervention, respectively. First, $1 \mu \mathrm{g}$ of total RNA was reverse transcribed into cDNA, using SuperScript II Reverse Transcriptase kit (Invitrogen Canada, Burlington, ON, Canada), and 50 ng of cDNA were used for polymerase chain reaction (PCR). Primer forward and reverse sequences for LPL were 5'-ACACAGCTGAGGACACTTGC-3' and 5'-CACTGGGTAATGCTCCTGAG-3', respectively. PCR consisted in an initial denaturation step at $95{ }^{\circ} \mathrm{C}$ for $2 \mathrm{~min}$, followed by 30 cycles composed of $20 \mathrm{~s}$ at $95^{\circ} \mathrm{C}$, $20 \mathrm{~s}$ annealing at $64{ }^{\circ} \mathrm{C}$, and $20 \mathrm{~s}$ elongation at $72{ }^{\circ} \mathrm{C}$. Reaction was heated between 72 and $99^{\circ} \mathrm{C}$, rising each step by $1{ }^{\circ} \mathrm{C}$ for $5 \mathrm{~s}$ to obtain the melting curve and to confirm a single product of PCR. AT-LPL mRNA levels were quantitated by fluorescent PCR on a Rotor Gene 3000 (Corbett Research, Montreal Biotech, Kirkland, QC, Canada), using the SYBR Green Jump Start TAQ ready mix (Sigma-Aldrich) and normalized to glyceraldehyde phosphate dehydrogenase whose primer forward and reverse sequences were 5'-ATCACCCCTTCATTGACCTCAAC-3' and 5'-GGTTCACACCCATGACGAACATG-3', respectively. All measurements were performed in duplicates $[32,33]$.

Anthropometry and Body Composition

Body weight and height were measured as previously described [29], and BMI calculated as the ratio of weight $(\mathrm{kg})$ to height $\mathrm{t}^{2}\left(\mathrm{~m}^{2}\right)$. Waist girth was measured at the narrowest circumference of the trunk according to standardized procedures. Since the pioneering work of Lemieux et al. [34], waist circumference was shown to be a stronger anthropometric correlate of abdominal visceral AT than waist-to-hip ratio (WHR) as it did not appear to be significantly influenced by gender nor by the obesity degree. Moreover, the use of waist girth instead of WHR to more accurately estimate the crude visceral abdominal fat accumulation and its related coronary heart disease risk has been largely emphasized during the last decade, as waist circumference is one of the 5 clinical criteria selected to determine the presence of metabolic syndrome, according to the NCEP-ATP III guidelines (2001) [35]. Fat mass and lean mass were determined by a standard bioelectrical impedance technique (Bodystat 1500, Isle of Man, UK) [36]. All measurements were performed in triplicate, and then averaged.

\section{Cardiorespiratory Fitness}

Cardiorespiratory fitness (CRF) was assessed by the 2-km walking test which was validated on moderately fit and obese but otherwise healthy men and women 20-65 years old [37]. Estimated maximal oxygen uptake $\mathrm{VO}_{2} \max (\mathrm{ml} / \mathrm{kg} / \mathrm{min})$ was calculated based on sex-specific prediction models which included walking time, $\mathrm{HR}$ at the end of the walk, age, and BMI. Equation used to predict $\mathrm{VO}_{2}$ max in women was the following: $\mathrm{VO}_{2} \max (\mathrm{ml} / \mathrm{kg} / \mathrm{min})=116.2-2.98 \times$ time $-0.11 \times \mathrm{HR}-0.14 \times$ age -0.39 $\times$ BMI, where time is the elapsed time for a walk in minutes, HR is the value at the end of the walk (beats/min), age is expressed in years and BMI in $\mathrm{kg} / \mathrm{m}^{2}$.

\section{Plasma Determinations}

Blood was collected from an antecubital vein in the morning after a 12hour overnight fast and a 15 -min rest period, and plasma samples were stored at $-80^{\circ} \mathrm{C}$ until use. Women had to remain inactive for $36 \mathrm{~h}$ to eliminate any acute effect of exercise on the metabolic profile before our postintervention [31]. Fasting total cholesterol, triacyglycerol (TAG) and HDL cholesterol levels were determined according to standardized laboratory procedures on a Technicon RA-500 analyzer (Bayer, Tarrytown, NJ, USA). Apolipoprotein B was measured by nephelometry (BN ProSpec; Dade Behring, Newark, DE, USA) with reagents provided by this company (N Antisera to Human Apolipoprotein B). Fasting low-density lipoprotein (LDL) cholesterol concentrations were estimated using the Friedewald equation [38]. Plasma FSH concentrations were determined by a radioimmunoassay kit (Diagnostic System Laboratories, Webster, TX, USA) while estradiol levels were measured by a competitive immunological assay (Immuno-1 apparatus, Bayer). Fasting blood sample measurements were performed irrespective of premenopausal women's menstrual cycle. 
Table 2. Subjects' physical characteristics before and after our walking program (means $\pm \mathrm{SD}$ )

\begin{tabular}{|c|c|c|c|c|}
\hline & \multicolumn{2}{|c|}{$\begin{array}{l}\text { Premenopausal women } \\
(\mathrm{n}=16)\end{array}$} & \multicolumn{2}{|c|}{$\begin{array}{l}\text { Postmenopausal women } \\
(\mathrm{n}=14)\end{array}$} \\
\hline & before & after & before & after \\
\hline Age, years & $49.0 \pm 2.0^{\mathrm{a}}$ & - & $52.0 \pm 2.0$ & - \\
\hline Body weight, $\mathrm{kg}$ & $81.9 \pm 9.8$ & $79.9 \pm 10.2^{\mathrm{c}}$ & $77.1 \pm 5.5$ & $76.5 \pm 5.7^{\mathrm{b}}$ \\
\hline BMI, $\mathrm{kg} / \mathrm{m}^{2}$ & $31.9 \pm 3.0$ & $31.1 \pm 3.2^{\mathrm{c}}$ & $30.8 \pm 1.9$ & $30.5 \pm 2.0^{\mathrm{b}}$ \\
\hline Waist girth, $\mathrm{cm}$ & $97.8 \pm 8.8$ & $95.2 \pm 9.5^{\mathrm{e}}$ & $98.1 \pm 6.3$ & $95.0 \pm 5.8^{\mathrm{e}}$ \\
\hline Fat mass, $\mathrm{kg}$ & $35.3 \pm 6.6$ & $33.8 \pm 6.6^{\mathrm{d}}$ & $33.8 \pm 4.6$ & $32.8 \pm 4.6^{\mathrm{d}}$ \\
\hline Lean mass, $\mathrm{kg}$ & $46.6 \pm 4.4$ & $46.1 \pm 4.5$ & $43.3 \pm 2.7$ & $43.7 \pm 3.1$ \\
\hline $\mathrm{VO}_{2} \max , \mathrm{ml} / \mathrm{kg} / \mathrm{min}$ & $20.2 \pm 5.4$ & $24.1 \pm 4.8^{\mathrm{e}}$ & $19.1 \pm 5.3$ & $22.7 \pm 4.6^{\mathrm{e}}$ \\
\hline \multicolumn{5}{|c|}{ Regional fat cell weight, $\mu \mathrm{g}$ lipid/cell } \\
\hline Abdominal & $0.64 \pm 0.17$ & $0.69 \pm 0.17$ & $0.77 \pm 0.20$ & $0.78 \pm 0.20$ \\
\hline Femoral & $0.77 \pm 0.37$ & $0.62 \pm 0.14$ & $0.73 \pm 0.19$ & $0.76 \pm 0.25$ \\
\hline
\end{tabular}

${ }^{\mathrm{a}} \mathrm{p}<0.001$ : significant difference between pre- and postmenopausal women at baseline. ${ }^{\mathrm{b}} \mathrm{p}<0.05 ;{ }^{\mathrm{c}} \mathrm{p}<0.01 ;{ }^{\mathrm{d}} \mathrm{p}<0.001 ;{ }^{\mathrm{e}} \mathrm{p}<0.0001$ : significant difference before and after walking, after adjustment for age.
Table 3. Subjects' hormonal and lipidlipoprotein profiles before and after our walking program (means $\pm \mathrm{SD}$ )

\begin{tabular}{|c|c|c|c|c|}
\hline & \multicolumn{2}{|c|}{$\begin{array}{l}\text { Premenopausal women } \\
(\mathrm{n}=16)\end{array}$} & \multicolumn{2}{|c|}{$\begin{array}{l}\text { Postmenopausal women } \\
(\mathrm{n}=14)\end{array}$} \\
\hline & before & after & before & after \\
\hline FSH, IU/l & $12.82 \pm 18.72^{\mathrm{a}}$ & $16.67 \pm 15.13$ & $81.76 \pm 22.72$ & $81.91 \pm 16.81$ \\
\hline Estradiol, pmol/1 & $424.47 \pm 317.25^{\mathrm{b}}$ & $551.40 \pm 396.08$ & $77.93 \pm 46.77$ & $68.00 \pm 25.12$ \\
\hline Triacylgycerol, mmol/1 & $1.14 \pm 0.59$ & $1.25 \pm 0.69$ & $1.46 \pm 0.74$ & $1.54 \pm 0.90$ \\
\hline Cholesterol, mmol/l & $5.28 \pm 1.07$ & $4.72 \pm 1.07^{\mathrm{c}}$ & $5.54 \pm 1.02$ & $5.48 \pm 1.08^{\mathrm{c}}$ \\
\hline LDL cholesterol, mmol/l & $3.33 \pm 0.92$ & $2.98 \pm 0.65^{\mathrm{c}}$ & $3.35 \pm 0.78$ & $3.33 \pm 0.79$ \\
\hline HDL cholesterol, mmol/l & $1.41 \pm 0.29^{\mathrm{b}}$ & $1.35 \pm 0.28^{\mathrm{c}}$ & $1.52 \pm 0.49$ & $1.43 \pm 0.46^{\mathrm{c}}$ \\
\hline CHOL/HDL cholesterol & $3.86 \pm 1.05$ & $3.74 \pm 0.77$ & $3.92 \pm 1.17$ & $4.12 \pm 1.23$ \\
\hline Apolipoprotein B, g/1 & $0.98 \pm 0.20$ & $0.99 \pm 0.17$ & $1.05 \pm 0.25$ & $1.06 \pm 0.20$ \\
\hline
\end{tabular}

$\mathrm{FSH}=$ Follicle stimulating hormone $; \mathrm{LDL}=$ low-density lipoprotein $; \mathrm{HDL}=$ high-density lipoprotein $; \mathrm{CHOL}=$ cholesterol. ${ }^{\mathrm{a}} \mathrm{p}<0.0001 ;{ }^{\mathrm{b}} \mathrm{p}<0.01$ : significant difference between pre- and postmenopausal women at baseline, after adjustment for age. ${ }^{c} \mathrm{p}<0.05$ : significant difference before and after walking, after adjustment for age.
Statistical Analyses

Results are given as means \pm standard error (SE) in figures and as means \pm standard deviation $(\mathrm{SD})$ in tables. Complete data were recorded on 30 participants (16 late pre- and 14 early postmenopausal women) through our study. Comparison of AT-LPL activity and expression, body composition, $\mathrm{CRF}$, and lipid-lipoprotein profile before and after walking was performed with a one-way (e.g. pre- vs. postmenopausal status) or a twoway covariance analysis (ANCOVA) with repeated measures and age as a covariable, using the general linear model procedure. Finally, relationships between variables were quantified using Pearson's product moment correlation coefficients. All analyses were conducted with the SAS statistical computer program package (SAS Institute, Carry, NC, USA). Statistical significance was set at $\mathrm{p}<0.05$.

\section{Results}

\section{Subjects' Characteristics}

As shown in table 2, comparison between groups did not reveal any difference in anthropometry, body composition, estimated $\mathrm{VO}_{2}$ max, and regional fat cell weight, at baseline $(0.18<\mathrm{p}<0.98)$. As expected, total adiposity was reduced after training, in both groups. Body weight loss of $-2.0 \pm 2.2$ versus $0.6 \pm 1.1 \mathrm{~kg}$ (means $\pm \mathrm{SD}$ ) and BMI decrease of $-0.8 \pm$ $0.9 \mathrm{~kg} / \mathrm{m}^{2}$ versus $-0.3 \pm 0.4 \mathrm{~kg} / \mathrm{m}^{2}$ were higher in pre- than in postmenopausal women, respectively $(0.005<\mathrm{p}<0.05)$. Although fat mass loss was comparable $(p<0.001)$, lean mass remained unchanged after walking, in both groups $(\mathrm{p}=0.79)$. Waist girth was similarly reduced after our intervention, in all women ( $p<0.0001)$. Finally, subcutaneous abdominal and femoral fat cell weight did not change in response to endurance exercise, regardless of menopausal status $(0.40<\mathrm{p}<0.52)$.

\section{Subjects' Hormonal and Lipid-Lipoprotein Profiles}

As illustrated in table 3, plasma FSH and estradiol levels were obviously different between pre- and postmenopausal women $(0.0001<\mathrm{p}<0.01)$. With the exception of plasma HDL cholesterol concentrations being slightly lower in pre- than in postmenopausal women $(\mathrm{p}<0.01)$ at baseline, the lipid-lipoprotein profile was comparable $(0.17<\mathrm{p}<0.71)$. Fasting plasma cho- 

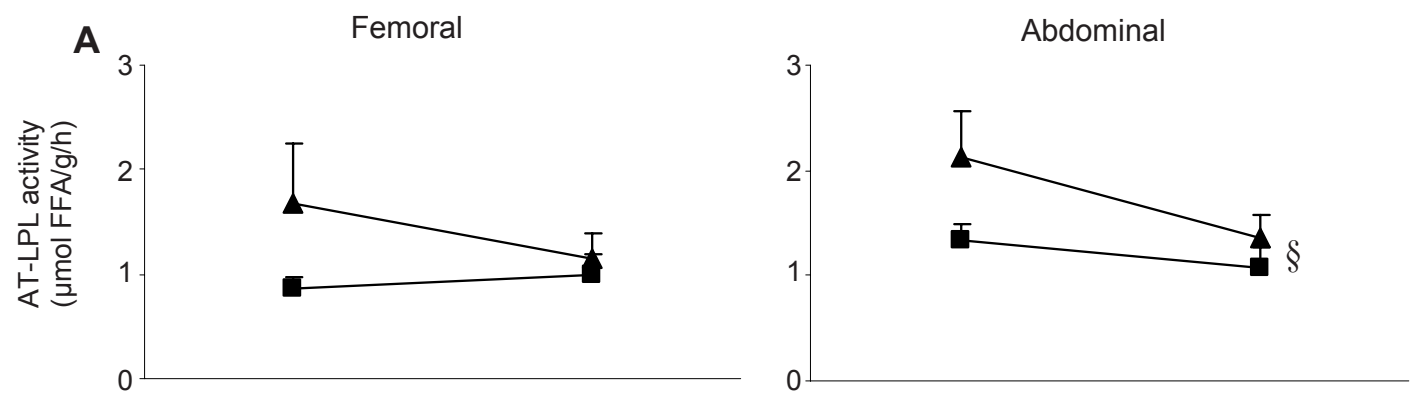

Fig. 1. Adipose tissue lipoprotein lipase (AT-LPL) activity expressed either per adipose tissue mass (A), per cell number (B) or corrected for variation in adipocyte surface area (C) in subcutaneous abdominal and femoral regions of pre- (ם) and postmenopausal ( $\mathbf{\Delta})$ women, before and after walking. Values are means \pm S.E. ${ }^{\S}, *$ Indicate significant differences within each group, before and after walking at $\mathrm{p}<0.005$ and at $\mathrm{p}<$ 0.05 , respectively.

B
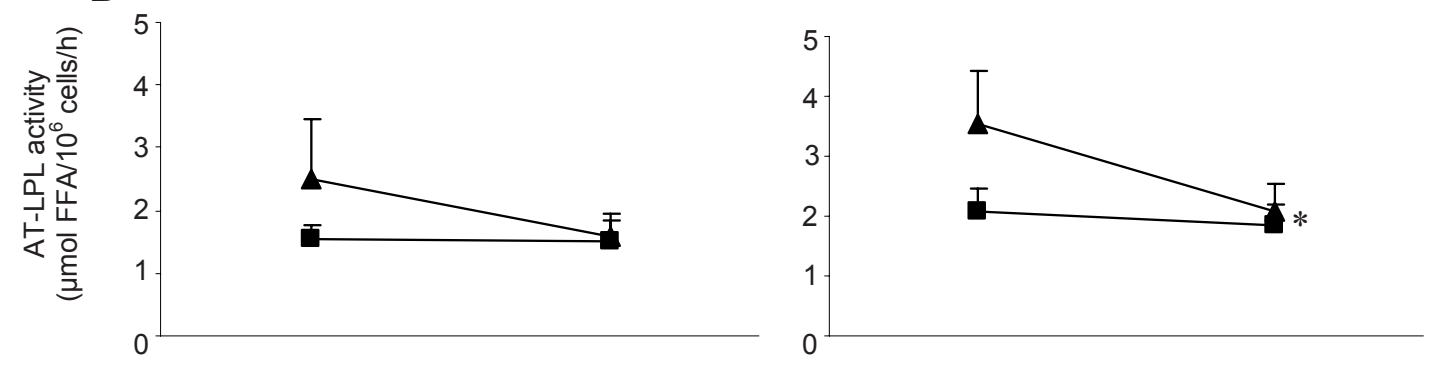

\section{C}

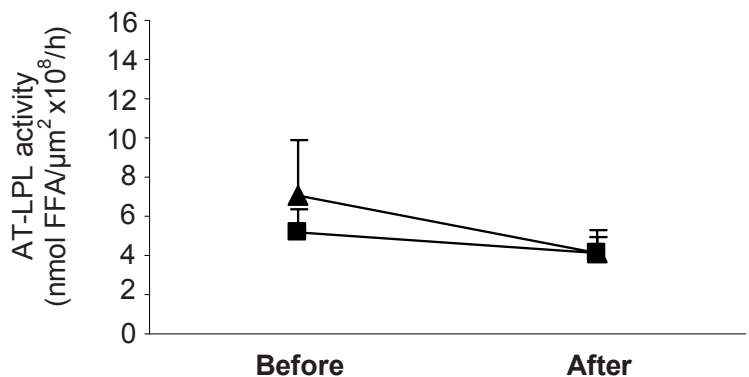

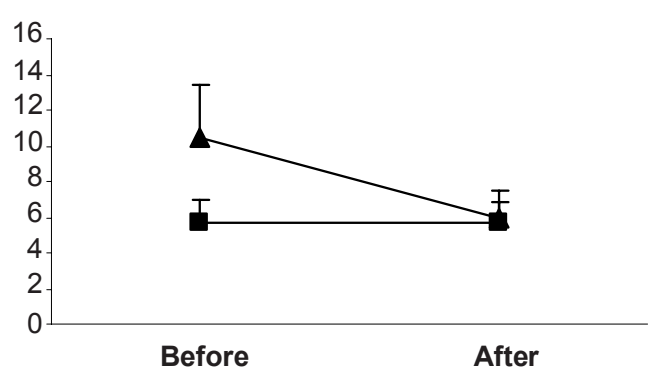

lesterol and HDL cholesterol levels were decreased in all subjects $(\mathrm{p}<0.05)$, whereas LDL cholesterol concentrations were reduced after walking in premenopausal women, exclusively $(\mathrm{p}<0.05)$. Moreover, plasma estradiol levels remained unchanged after our intervention, in both groups.

\section{Adipose Tissue-Lipoprotein Lipase Activity and Expression}

Figure 1 illustrates the effect of our walking program on ATLPL activity expressed either per AT mass, per cell number, or corrected for variation in cell surface area, in subcutaneous abdominal and femoral adipose regions of pre- and postmenopausal women. No regional variation was found in the initial AT-LPL activity, regardless of data expression and menopausal status $(0.08<\mathrm{p}<0.88)$. A decrease in femoral AT-LPL activity when expressed per AT mass or cell number was observed in response to our intervention, in both groups $(0.005<\mathrm{p}<0.05)$. However, this enzyme activity measured in the abdominal fat depot did not change after walking, in both groups $(0.10$ $<\mathrm{p}<0.33$ ). As shown in figure 2, AT-LPL expression was also similar in pre- and postmenopausal women, regardless of the fat depot $(0.15<\mathrm{p}<0.28)$. Both pre- and postmenopausal displayed reduced enzyme mRNA levels at the femoral site after walking $(\mathrm{p}<0.01)$, but not at the abdominal level $(\mathrm{p}=0.42)$.

\section{Relationships between Adipose Tissue-Lipoprotein}

\section{Lipase Activity and Expression}

The extent of the fall in LPL activity observed after our intervention in the femoral (but not in the abdominal) fat depot was associated with the initial level of enzyme activity. Figure 3 shows that the higher was the initial femoral AT-LPL activity, the greater was its reduction when expressed per AT mass or per cell number in pre- and postmenopausal women considered together $(-0.82<\mathrm{r}<-0.74 ; \mathrm{p}<0.0001)$. The decrease in femoral AT-LPL mRNA levels was also negatively related to the baseline enzyme expression $(\mathrm{r}=-0.56$; $\mathrm{p}<0.005)$. Changes in femoral AT-LPL expression were positively related to those in its activity when expressed per AT mass, only $(\mathrm{r}=0.41 ; \mathrm{p}<0.05)$. However, there was no significant association between femoral AT-LPL mRNA levels and the enzyme activity assessed at baseline $(-0.23<\mathrm{r}<-0.21)$. Similar data were observed at the abdominal site (not shown).

\section{Relationships between Changes in Adipose Tissue-}

Lipoprotein Lipase Activity and/or Expression and LipidLipoprotein Metabolism

Reductions in the femoral AT-LPL activity or expression were associated neither with the slight reduction in plasma LDL 
Fig. 2. Adipose tissue lipoprotein lipase expression (AT-LPL mRNA levels) in subcutaneous abdominal and femoral regions of pre- (ם) and postmenopausal ( $\mathbf{\Delta}$ ) women, before and after walking. Values are means \pm S.E. ${ }^{\dagger}$ Indicates a significant difference within each group, before and after walking at $\mathrm{p}<0.01$.
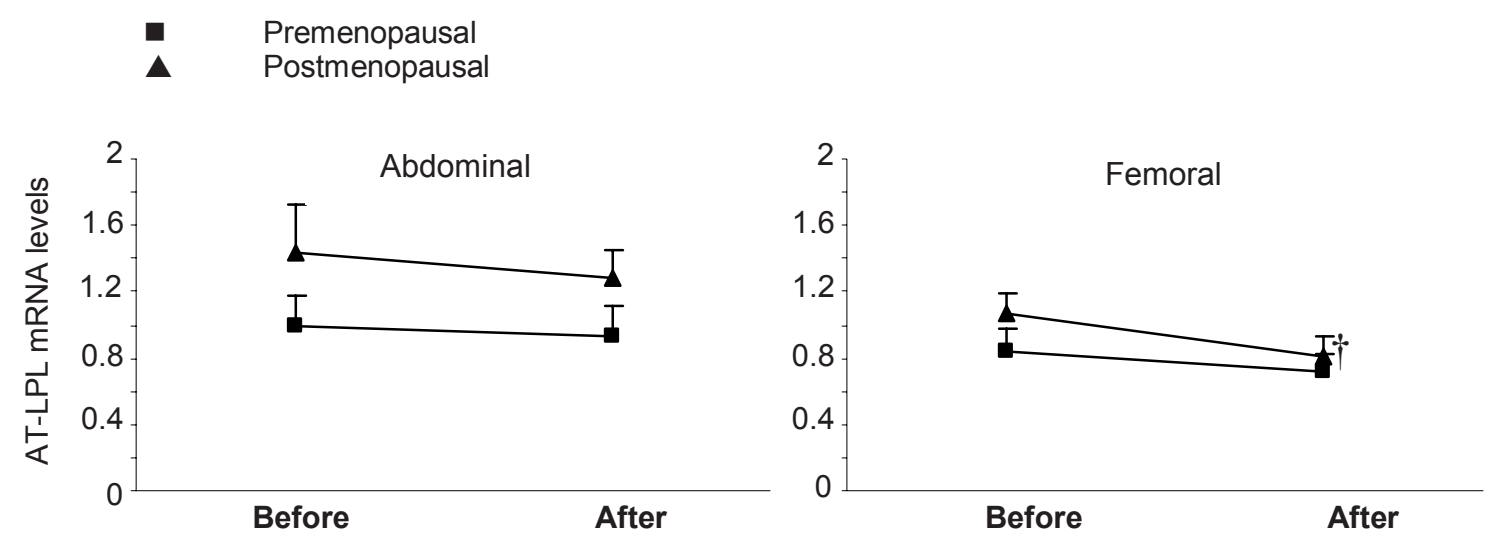

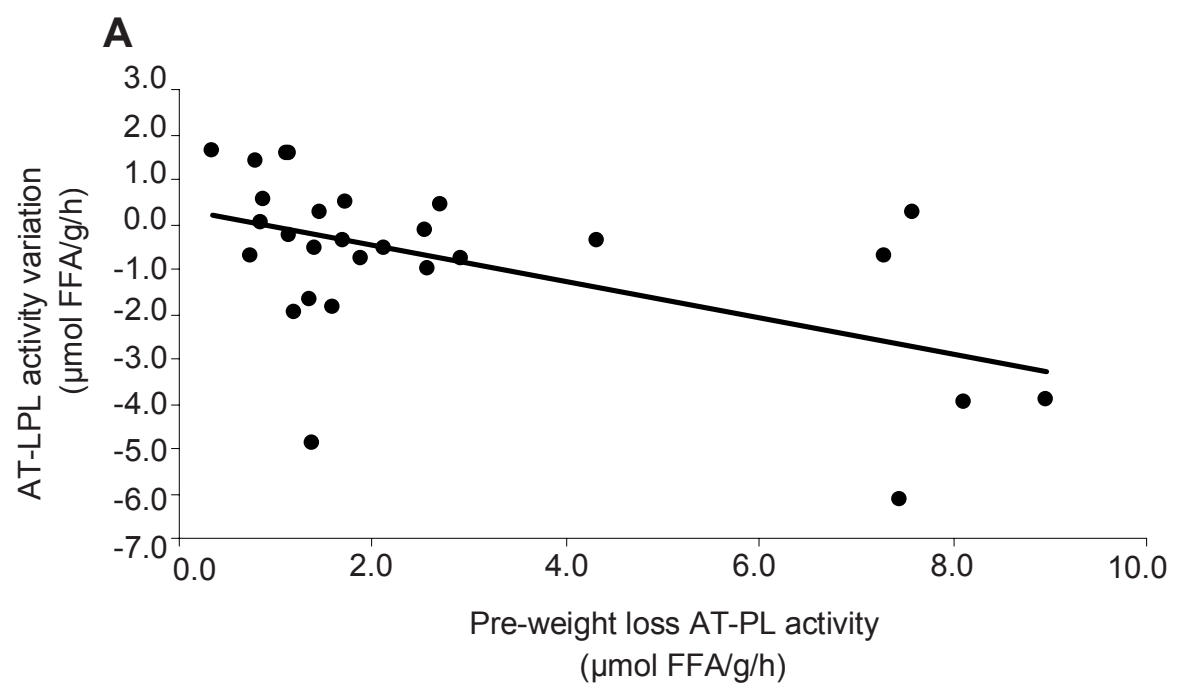

B

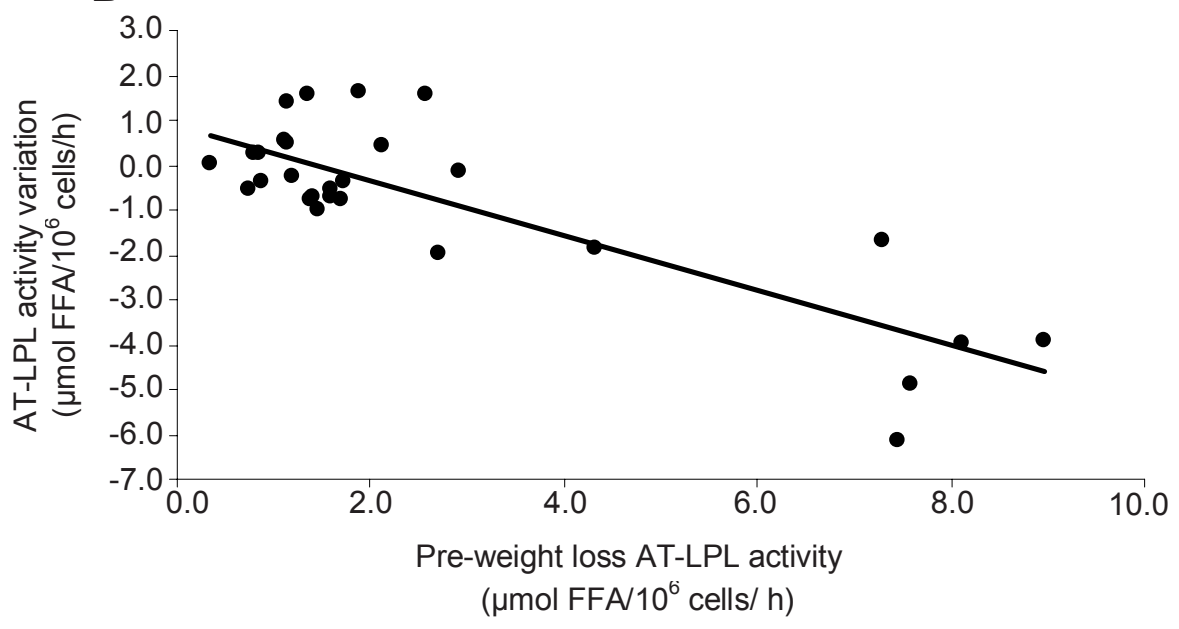

Fig. 3. Relationships between changes in ATLPL activity and the initial enzyme activity expressed either per adipose tissue mass (A) or per cell number (B), in the femoral adipose region of pre- and postmenopausal women.

cholesterol levels $(-0.34<\mathrm{r}<-0.26$; $0.08<\mathrm{p}<0.18)$ nor with the modest decrease in HDL cholesterol concentrations $(-0.15$ $<\mathrm{r}<-0.06 ; 0.46<\mathrm{p}<0.77)$ noted after our intervention. No significant relationship was found between changes in these lipid-lipoprotein variables and variation in the enzyme activity or expression assessed at the abdominal site (not shown).

\section{Discussion}

To the best of our knowledge, our study is the first to investigate the impact of aerobic exercise-induced weight loss on regional variation in AT-LPL activity and expression, after having carefully controlled for differences in women's chronolog- 
ical age and obesity degree. Our results showed that the enzyme activity and its expression in the femoral (but not the abdominal) fat depot decreased similarly in response to our walking program, regardless of menopausal status.

The comparable fat cell size and AT-LPL activity noted in premenopausal women, irrespective of the region considered, is in contrast with previous $[6,7]$, but not all observations [5, 39]. Controversies between our findings and those of RebufféScrive et al. [7] could be due to the fact that the latter premenopausal women were younger (mean age of $30 \pm 2$ years), leaner (mean BMI of $\left.23.7 \pm 0.6 \mathrm{~kg} / \mathrm{m}^{2}\right)($ mean $\pm \mathrm{SE}$ ) than our participants (table 2). Also, their AT-LPL activity was measured while women were either in the follicular or in the luteal phase of their menstrual cycle, Similarly, conflicting data between our study and the one of Raison et al. [6] could be attributed to differences in women's age ( $38 \pm 2$ years) and obesity degree $\left(35.2 \pm 2 \mathrm{~kg} / \mathrm{m}^{2}\right)$, as well as to the fact that fat biopsies and LPL measurements were done during women's luteal phase (i.e. between the 19th and 25th days of their menstrual cycle). In this regard, AT biopsies and enzyme assays were performed during the follicular phase of our subjects (i.e., between the 5th and 12th days of their menstrual cycle). Although the lack of regional variation in both fat cell weight and enzyme activity of postmenopausal women has largely been documented [7, 11-13, 39], it is not concordant with some studies $[6,9,16]$ probably because of subjects' fatness and age, duration of menopause, the use or not of HT, its mode of administration (oral vs. transdermal), as well as to the fact that estrogens were administered alone and/or combined with progesterone. In this regard, RebufféScrive et al. [11] and Lindberg et al. [13] clearly showed that HT was able to restore high fat cell size and AT-LPL activity in the femoral depot, when compared to the abdominal region. The fact that pre- and postmenopausal women had comparable fat cell size and AT-LPL activity is easily explainable by their physical characteristics at baseline (table 1), and concordant with previous reports $[39,40]$. The lack of regional variation in AT-LPL mRNA abundance could also be partly explained by subjects' fatness, as Arner et al. [14] already found higher LPL mRNA abundance in the gluteal than in the abdominal region of premenopausal non obese women. It is surprising that AT-LPL activity does not vary according to menopausal status, as plasma estradiol levels differ between pre- and postmenopausal women. However, no relationship was observed between the enzyme activity and plasma estradiol levels in the present study. In this regard, high estradiol levels were already shown to decrease abdominal AT-LPL activity while low doses had the opposite effects [41], although in vitro incubation of AT fragments with estradiol reduced the enzyme activity [42]. The use of whole AT fragments [42] instead of isolated adipocytes [41] could provide a valuable explanation for these conflicting data. Further experiments that will examine the influence of sex steroids on changes in AT-LPL activity with menopause transition are clearly warranted.
The fact that femoral (but not abdominal) AT-LPL activity was significantly reduced after walking, in the absence of reduced fat cell size and despite modest body weight and fat mass losses, could also be questioned. In this regard, attention should be paid to the preferential abdominal fat cell weight reduction reported after diet combined with aerobic exercise, in obese women [43]. Indeed, although gluteal adipocyte size decreased similarly in response to diet alone or associated with either low- or high-intensity exercise, subcutaneous abdominal fat size was preferentially reduced in combined weight loss interventions [43]. Moreover, the decrease in femoral AT-LPL activity noted after our 16-week walking program is concordant with previous reports $[5,15,21,44]$ but contrasts with others which showed a lack of change $[10,16$, 17], or an increase in the enzyme activity [18-20]. Such discrepancy could be due to the substantial mean weight loss achieved reported in the 3 latter studies [18-20] or to subjects' fatness, nature, and duration of the restrictive diet used to promote weight loss, combination of caloric restriction and aerobic exercise [10, 16, 17]. The negative relationship observed between the fall in LPL activity and the pre-weight loss enzyme activity has been frequently observed among studies reporting a decrease in AT-LPL activity [5, 15, 16, 21, 44]. Our results also revealed a reduction in femoral AT-LPL expression following endurance exercise, in both groups. Although this result is not in agreement with the similar postweight loss enzyme expression reported by our group [5], such discrepancy could be due to the techniques used (Northern blot analysis versus RT-PCR) and/or to women's age differences. In the present study, the higher the decrease in femoral AT-LPL expression, the greater the reduction in the enzyme activity, thus suggesting that changes may occur at a transcriptional level. However, as expression of LPL involves several steps such as gene transcription, processing, transport, and translation of mRNA as well as post-translational modifications, secretion, and extra-cellular activation of the enzyme [3] should be considered [14, 45]. Further studies measuring AT-LPL mass are needed to address this issue.

A decrease in AT-LPL activity after weight loss could lead to a reduction in TAG clearance, thus resulting in higher TAG as well as lower plasma HDL and LDL cholesterol concentrations. The lack of clear relationships between changes in plasma TAG levels and variation in AT-LPL activity has already been reported by us [5] and others [16], in pre- and postmenopausal women, respectively. In this regard, results of studies investigating the effect of caloric restriction combined with lipid-lowering drugs or exercise on plasma TG levels indicated that reductions in fasting TAG levels were associated with skeletal muscle rather than with AT-LPL activity [46]. On the other hand, we did not observe any association between variation in AT-LPL activity and changes in LDL and/ or in HDL cholesterol levels, despite the slight reductions in these plasma lipoprotein levels after walking (table 3). This finding is in contrast with the positive relationship found be- 
tween the decrease in femoral AT-LPL activity and the reduction in plasma HDL cholesterol concentrations after weight loss, already found in young premenopausal women by our group [5]. Although not statistically significant, similar trends for a decrease in plasma HDL cholesterol concentrations associated with a reduction in gluteal AT-LPL activity were already observed in postmenopausal women [16]. It is true that a high femoral or gluteal AT-LPL activity in pre- and postmenopausal women may increase the proportion of cholesterol ester remaining associated with HDL, the protective lipoprotein fraction against coronary heart disease $[8,12]$. Therefore, the decrease in the femoral AT-LPL activity observed in our participants could be considered as deleterious from a clinical standpoint as HDL cholesterol concentrations were slightly reduced after walking. However, these values higher than the threshold defined by the NCEP-ATP III [35] still attested of a favourable lipid-lipoprotein profile. Finally, women whose abdominal and gluteal AT-LPL activities were reduced with weight loss regained less body weight at followup, thus suggesting that energy storage efficiency was decreased in the weight-reduced state of these women [16]. Regarding these findings, it should be thus hypothesized that weight regain will be less important in our participants.

Finally, the difference between groups of $7.7 \%$ in baseline HDL cholesterol levels, although being clinically marginal, reflected a favourable lipid-lipoprotein profile, as values recorded were above the threshold of $1.3 \mathrm{mmol} / \mathrm{l}$ defined by the NCEP/ATP III guidelines (2001) [35]. In addition, although waist girth values were above the NCEP-ATP III threshold, this criterion similarly decreased in all women, after our walking program. However, the fact that waist circumference was still higher than $88 \mathrm{~cm}$, clearly attested of a subcutaneous abdominal rather than a visceral obesity [47]. Indeed, Lemieux et al. [48] have already proposed that the 'hypertriglyceridemic waist' (e.g. elevated waist circumference combined with high fasting TAG levels) should better identify individuals with an excessive visceral fat accumulation and the related features of metabolic syndrome. As plasma TAG levels were below the threshold of $1.7 \mathrm{mmol} / \mathrm{l}$ [35], our participants were probably characterized by a subcutaneous abdominal form of obesity, irrespective of their menopausal status.

Some limitations may, however, deserve further attention. Indeed, bioelectrical impedance was used to assess body composition instead of other methods more sophisticated such as DEXA. However, leg-to-leg bio-impedance has been validated during weight loss interventions conducted in overweight and obese individuals [49]. Estimated $\mathrm{VO}_{2}$ max was also extrapolated from the 2-km walking test (a sub-maximal exercise test), and some error should have thus been introduced as the equation used to predict $\mathrm{VO}_{2}$ max took into account variables such as elapsed time and $\mathrm{HR}$ at the end of a 2-km walk, and BMI [37]. However, the 2-km walking test was considered by the same group as a valid tool for predicting $\mathrm{VO}_{2}$ max changes after a 15 -week walking program in mid- dle-aged and healthy individuals [50]. On the other hand, reduction in fasting cholesterol levels could be probably considered as not clinically relevant, as the value reported $(\mathrm{p}=.049)$ was of borderline significance. Such findings could be partly explained by the small number of participants $(n=30)$. In this regard, the two sets of fat biopsies planned before and after our endurance exercise program represented an invasive intervention which may have limited the number of volunteers. Finally, although blood sample measurements should have been performed while premenopausal women were in the follicular phase of their menstrual cycle (e.g. between the 5th and the 12th days of their menstrual cycle), this was not possible because of our participants' time constraints. Such an observation could provide an additional explanation to the wide range of variation observed in plasma FSH levels (table 3).

Our study also has several strengths such as the fact that women walked in indoor community facilities under the supervision of an exercise physiologist, 3 times per week, during which exercise intensity was continuously monitored through $\mathrm{HR}$, and $\mathrm{HR}$ values were recorded in an exercise log book to ensure compliance with the training intensity. In addition, comparison of late pre- and early postmenopausal women with a narrow age difference allows better understanding of the effects of menopause on lipid storage capacities [40].

\section{Conclusion}

This study documents for the first time that both the LPL activity and mRNA level of the femoral (but not the subcutaneous abdominal) AT are similar, regardless of menopausal status, once chronological age and obesity degree are taken into account. Our 16-week walking program also seems to be sufficient to reduce lipid storage in the femoral fat depot of late pre- and early postmenopausal women. Finally, reduction in femoral AT-LPL activity does not lead to a more deleterious lipid-lipoprotein profile, despite the modest decrease observed in plasma HDL cholesterol levels.

\section{Acknowledgements}

This study was supported by the Canadian Institutes of Health Research (CIHR). The cooperation of subjects who participated to this walking program was greatly appreciated. We also gratefully thank Claude Leblanc for his statistical analyses. This study was supported by the operating grant \# MOP-77572 obtained from CIHR. Thanks are also expressed to Alexandra Andersen, Denise Christen, Katie Lacasse, Geneviève Ouellet, Renaud Turcotte-Sabourin, Guillaume Salamin, and Jean Tremblay for their very helpful assistance in the supervision of walking sessions.

\section{Disclosure}

The authors declared no conflict of interest.
Tessier/Riesco/Lacaille/Pérusse/Weisnagel/ Doré/Mauriège 


\section{References}

1 Bouchard C, Després JP, Mauriège P: Genetic and nongenetic determinants of regional fat distribution. Endocr Rev 1993;14:72-93.

2 Leibel RL, Edens NK, Fried SK: Physiologic basis for the control of body fat distribution in humans. Annu Rev Nutr 1989;9:417-443.

$\checkmark 3$ Eckel RH: Lipoprotein lipase. A multifunctional enzyme relevant to common metabolic diseases. N Engl J Med 1989;320:1060-1068.

$\checkmark 4$ Svendsen OL, Hassager C, Christiansen C: Ageand menopause-associated variations in body composition and fat distribution in healthy women as measured by dual-energy x-ray absorptiometry. Metabolism 1995;44:369-373.

$\checkmark 5$ Imbeault P, Alméras N, Richard D, Després JP, Tremblay A, Mauriège P: Effect of a moderate weight loss on adipose tissue lipoprotein lipase activity and expression: existence of sexual variation and regional differences. Int J Obes Relat Metab Disord 1999;23:957-965.

6 Raison J, Basdevant A, Sitt Y, Guy-Grand B: Regional differences in adipose tissue lipoprotein lipase activity in relation to body fat distribution and menopausal status in obese women. Int J Obes 1988;12:465-472.

7 Rebuffé-Scrive M, Eldh J, Hafstrom LO, Björntorp P: Metabolism of mammary, abdominal, and femoral adipocytes in women before and after menopause. Metabolism 1986;35:792-797.

$\checkmark 8$ St-Amand J, Després JP, Lemieux S, Lamarche B, Moorjani S, Prud'homme D, Bouchard C, Lupien PJ: Does lipoprotein or hepatic lipase activity explain the protective lipoprotein profile of premenopausal women? Metabolism 1995;44:491-498.

9 Ferrara CM, Lynch NA, Nicklas BJ, Ryan AS, Berman DM: Differences in adipose tissue metabolism between postmenopausal and perimenopausal women. J Clin Endocrinol Metab 2002;87:4166-4170.

10 Berman DM, Nicklas BJ, Ryan AS, Rogus EM, Dennis KE, Goldberg AP: Regulation of lipolysis and lipoprotein lipase after weight loss in obese, postmenopausal women. Obes Res 2004;12:32-39.

11 Rebuffé-Scrive M, Lonnroth P, Marin P, Wesslau C, Björntorp P, Smith U: Regional adipose tissue metabolism in men and postmenopausal women. Int J Obes 1987;11:347-355.

12 Berman DM, Nicklas BJ, Rogus EM, Dennis KE, Goldberg AP: Regional differences in adrenoceptor binding and fat cell lipolysis in obese, postmenopausal women. Metabolism 1998;47:467-473.

13 Lindberg UB, Crona N, Silfverstolpe G, Bjorntorp P, Rebuffe-Scrive M: Regional adipose tissue metabolism in postmenopausal women after treatment with exogenous sex steroids. Horm Metab Res 1990;22:345-351.

14 Arner P, Lithell H, Wahrenberg H, Bronnegard M: Expression of lipoprotein lipase in different human subcutaneous adipose tissue regions. J Lipid Res 1991:32:423-429.

15 Rebuffé-Scrive M, Basdevant A, Guy-Grand B: Nutritional induction of adipose tissue lipoprotein lipase in obese subjects. Am J Clin Nutr 1983;37:974-980.

16 Nicklas BJ, Rogus EM, Berman DM, Dennis KE, Goldberg AP: Responses of adipose tissue lipoprotein lipase to weight loss affect lipid levels and weight regain in women. Am J Physiol Endocrinol Metab 2000;279:E1012-1019.

17 Sörbris R, Petersson BG, Nilsson-Ehle P: Effects of weight reduction on plasma lipoproteins and adipose tissue metabolism in obese subjects. Eur J Clin Invest 1981;11:491-498.

18 Kern PA, Ong JM, Saffari B, Carty J: The effects of weight loss on the activity and expression of adipose-tissue lipoprotein lipase in very obese humans. N Engl J Med 1990;322:1053-1059.

19 Kolehmainen M, Vidal H, Ohisalo JJ, Pirinen E, Alhava E, Uusitupa MI: Hormone sensitive lipase expression and adipose tissue metabolism show gender difference in obese subjects after weight loss. Int J Obes Relat Metab Disord 2002;26:6-16.

20 Schwartz RS, Brunzell JD: Increase of adipose tissue lipoprotein lipase activity with weight loss. J Clin Invest 1981;67:1425-1430.

21 Lamarche B, Després JP, Moorjani S, Nadeau A, Lupien PJ, Tremblay A, Thériault G, Bouchard $\mathrm{C}$ : Evidence for a role of insulin in the regulation of abdominal adipose tissue lipoprotein lipase response to exercise training in obese women. Int J Obes Relat Metab Disord 1993;17:255-261.

22 Patsch J: Influence of lipolysis on chylomicron clearance and HDL cholesterol levels. Eur Heart J 1998;19(suppl H):H2-6.

23 Henrich JB, Hughes JP, Kaufman SC, Brody DJ, Curtin LR: Limitations of follicle-stimulating hormone in assessing menopause status: findings from the national health and nutrition examination survey (NHANES 1999-2000). Menopause 2006;13:171-177.

24 Clinical challenges of perimenopause: consensus opinion of the North American menopause society. Menopause 2000;7:5-13.

25 Greendale GA, Lee NP, Arriola ER: The menopause. Lancet 1999;353:571-580.

26 Prior JC: Perimenopause: the complex endocrinology of the menopausal transition. Endocr Rev 1998; 19:397-428.

27 Soules MR, Sherman S, Parrott E, Rebar R, Santoro N, Utian W, Woods N: Executive summary: stages of reproductive aging workshop (STRAW). Climacteric 2001;4:267-272.

28 American College of Sports Medicine position stand. The recommended quantity and quality of exercise for developing and maintaining cardiorespiratory and muscular fitness, and flexibility in healthy adults. Med Sci Sports Exerc 1998;30:975-991.

29 Karvonen MJ, Kentala E, Mustala O: The effects of training on heart rate; a longitudinal study. Ann Med Exp Biol Fenn 1957;35:307-315.

30 Mauriège P, Prud'homme D, Lemieux S, Tremblay A, Després JP: Regional differences in adipose tissue lipolysis from lean and obese women: existence of postreceptor alterations. Am J Physiol 1995;269:E341-350.

31 Mauriège P, Prud'homme D, Marcotte M, Yoshioka M, Tremblay A, Després JP: Regional differences in adipose tissue metabolism between sedentary and endurance-trained women. Am J Physiol 1997;273:E497-506

32 Mauriège P, Gélinas Y, Lacaille M, Biron S, Richard $\mathrm{D}$, Picard M: Regional variation in adipose tissue secretory function of morbidly obese premenopausal women. 19th annual meeting of the North American Association for the study of obesity, Vancouver, Canada, October 2005. Obes Res 2005;13:A43.

33 Mauriège P, Lacaille M, Gélinas Y, Cartier A, Lemieux I, Bergeron J, Biron S, Marceau P, Richard D: Regional variation in visceral adipose tissue secretory function among morbidly obese premenopausal women. 17th European Congress on Obesity, Geneva, Switzerland, May 2008. Int J Obes 2008;32:S58.

34 Lemieux S, Prud'homme D, Bouchard C, Tremblay A, Després JP: A single threshold value of waist girth identifies normal-weight and overweight subjects with excess visceral adipose tissue. Am J Clin Nutr 1996;64:685-693.

35 NCEP: Executive summary of the third report of the national cholesterol education program (NCEP) expert panel on detection, evaluation, and treatment of high blood cholesterol in adults (adult treatment panel III). JAMA 2001;285:2486-2497.

36 Lemoine S, Rossell N, Drapeau V, Poulain M, Garnier S, Sanguignol F, Mauriège P: Effect of weight reduction on quality of life and eating behaviors in obese women. Menopause 2007;14:432-440.

37 Laukkanen R, Oja P, Pasanen M, Vuori I: Validity of a two kilometre walking test for estimating maximal aerobic power in overweight adults. Int J Obes Relat Metab Disord 1992;16:263-268.

38 Friedewald WT, Levy RI, Fredrickson DS: Estimation of the concentration of low-density lipoprotein cholesterol in plasma, without use of the preparative ultracentrifuge. Clin Chem 1972;18:499-502.

39 Mauriège P, Imbeault P, Prud'Homme D, Tremblay A, Nadeau A, Després JP: Subcutaneous adipose tissue metabolism at menopause: importance of body fatness and regional fat distribution. J Clin Endocrinol Metab 2000;85:2446-2454.

40 Tchernof A, Desmeules A, Richard C, Laberge P, Daris M, Mailloux J, Rheaume C, Dupont P: Ovarian hormone status and abdominal visceral adipose tissue metabolism. J Clin Endocrinol Metab 2004;89:3425-3430.

41 Palin SL, McTernan PG, Anderson LA, Sturdee DW, Barnett AH, Kumar S: 17beta-estradiol and anti-estrogen ICI:Compound 182,780 regulate expression of lipoprotein lipase and hormone-sensitive lipase in isolated subcutaneous abdominal adipocytes. Metabolism 2003;52:383-388.

42 Pedersen SB, Kristensen K, Hermann PA, Katzenellenbogen JA, Richelsen B: Estrogen controls lipolysis by up-regulating alpha2-adrenergic receptors directly in human adipose tissue through the estrogen receptor alpha. Implications for the female fat distribution. J Clin Endocrinol Metab 2004;89:1869-1878.

43 You T, Nicklas BJ: Chronic inflammation: role of adipose tissue and modulation by weight loss. Curr Diabetes Rev 2006;2:29-37.

44 Taskinen MR, Nikkila EA: Basal and postprandial lipoprotein lipase activity in adipose tissue during caloric restriction and refeeding. Metabolism 1987; 36:625-630.

45 Maheux P, Azhar S, Kern PA, Chen YD, Reaven GM: Relationship between insulin-mediated glucose disposal and regulation of plasma and adipose tissue lipoprotein lipase. Diabetologia 1997;40:850-858.

46 Seip RL, Angelopoulos TJ, Semenkovich CF: Exercise induces human lipoprotein lipase gene expression in skeletal muscle but not adipose tissue. Am J Physiol 1995;268:E229-236.

47 Després JP, Lemieux I, Bergeron J, Pibarot P, Mathieu P, Larose E, Rodes-Cabau J, Bertrand OF, Poirier P: Abdominal obesity and the metabolic syndrome: contribution to global cardiometabolic risk. Arterioscler Thromb Vasc Biol 2008;28:1039-1049.

48 Lemieux I, Pascot A, Couillard C, Lamarche B, Tchernof A, Almeras N, Bergeron J, Gaudet D, Tremblay G, Prud'homme D, Nadeau A, Després JP: Hypertriglyceridemic waist: a marker of the atherogenic metabolic triad (hyperinsulinemia; hyperapolipoprotein b; small, dense LDL) in men? Circulation 2000;102:179-184.

49 Jebb SA, Siervo M, Murgatroyd PR, Evans S, Fruhbeck G, Prentice AM: Validity of the legto-leg bioimpedance to estimate changes in body fat during weight loss and regain in overweight women: a comparison with multi-compartment models. Int J Obes 2007;31:756-762.

50 Laukkanen RM, Kukkonen-Harjula TK, Oja P, Pasanen ME, Vuori IM: Prediction of change in maximal aerobic power by the 2 -km walk test after walking training in middle-aged adults. Int J Sports Med 2000;21:113-116. 